\title{
Levels and Predictors of Adherence to Self-care Behaviour among Adult Type 2 Diabetics at Arba Minch General Hospital, Southern Ethiopia
}

\author{
Mende Sorato $\mathbf{M}^{*}$, Tesfahun $\mathbf{C}$ and Lamessa D
}

Arba Minch College of Health Sciences, Arba Minch, Ethiopia

\begin{abstract}
Background: Diabetes self-care behaviour adherence is considered to be the cornerstone in diabetes care. Hence, the success of long-term maintenance therapy for diabetes depends largely on the patients' adherence with self-care behaviour.

Objective: To assess Levels and Predictors of Adherence to self-Care Behaviour and Glycaemic Control among Adult Type 2 Diabetics at Arba Minch General Hospital, Southern Ethiopia.

Method: An institutional based cross sectional study was conducted from [15 $5^{\text {th }}$-February to $15^{\text {th }}-$ March, 2015] and data were collected by using interviewer administered questionnaires. The data were entered into EPI-DATA version 3.1, and analysed by Statistical Package for Social Science (SPSS) version 20.0. Descriptive statistics were used for most variables; a bivariate analysis was employed to determine the presence of association between adherence to self-care behaviour with other variables at $P$-value less than 0.05 . Multi-variable logistic regression was performed to identify independent predictors of glycaemic control and self-care behaviour adherence.

Results: One hundred ninty four type 2 diabetics were participated in this study and $99(51.0 \%)$ were Females. Mean age of participants was $50.3( \pm 13.2)$ years, and $41.2 \%$ had good self-care behaviour adherence. Above one half $(57.2 \%)$ had diabetes duration less than five years, with mean duration of diabetes $5.02 \pm 3.8$ years. Most of patients 169 (87.1\%) were on oral anti diabetics Age 35-44 years [AOR=13.4, 95\% Cl=1.582, 113.56], Monthly income $<750.00$ birr $[A O R=0.340,95 \% \mathrm{Cl}=0.119,0.976]$ and age at diabetes onset $15-24$ years $[A O R=11.3,95 \%$ $\mathrm{Cl}=2.621,49.065]$ were independent predictors of self-care behaviour adherence.

Conclusion: In our study area adherence to self-care behaviour of the study subjects were low. So strategies that can improve these discrepancies like provision of diabetes self-care education and counselling especially on importance of self-monitoring of blood glucose, physical activity and problem solving should be considered by responsible bodies.
\end{abstract}

Keywords: Type 2 diabetes; Self-care behaviour adherence; Ethiopia

Acronyms: AADEs: American Association of Diabetes Educators; ACEIS: Angiotensin Converting Enzyme Inhibitors; ADA: American Diabetes Association; BMI: Body Mass Index; BP: Blood Pressure; DKT: Diabetes Knowledge Test; DM: Diabetes Mellitus; EAG: Estimated Average Glucose; FBS: Fasting Blood Glucose; HbA1C: Haemoglobin Glycated/Glycosylated; IDF: International Diabetes Federation; JUSH: Jimma University Specialized Hospital; MMAS: Morisky Medication Adherence Scale; Ncds: Non-Communicable Disease; Ohas: Oral Hypoglycaemic Agents; OPD: Outpatient Department; RBS: Random Blood Glucose; SDSCA: Summary of Diabetes Self-Care Activities; SMBG: Self-Monitoring of Blood Glucose; TB: Tuberculosis; USD: United States Dollar; WHO: World Health Organization

\section{Introduction}

\section{Background}

Type 2 diabetes is a chronic disorder, which is characterized by hyperglycaemia and glycosuria. It affects 90 to $95 \%$ of sufferers, with onset usually after the age of 40 years [1,2]. High concentration of blood glucose can cause structural damages including macrovascular events in the heart and blood vessels as well as microvascular complications [3].

IDF Atlas $6^{\text {th }}$ edition 2013 showed that 382 million people worldwide are estimated to have diabetes and by 2035; 592 million people, or one adult in 10, will have diabetes [4-7]. Over the next 20 years, the developed world will see an increase of $20 \%$ in the number of adults living with diabetes and developing countries will see an increase of $69 \%[8,9]$.

Type 2 diabetes prevalence among 20-79-year-olds in African region is $4.9 \%$ with the majority of people with diabetes $<60$ years old [10]. Hence Sub-Saharan Africa faces a double burden of providing adequate care for both infectious diseases like malaria, tuberculosis and non-communicable diseases (NCDs) like diabetes and hypertension $[11,12]$.

Ethiopia experiences a heavy burden of disease mainly attributed to communicable infectious diseases and nutritional deficiencies [13-15]. However currently, Ethiopia is also challenged by the growing magnitude of chronic non communicable diseases. The national estimate made based on neighbouring countries with similar socio-economic situations showed that $2 \%-3 \%$ of the population had diabetes $[16,17]$.

*Corresponding author: Mende Sorato Mensa, Arba Minch College of Health Sciences, Arba Minch, Ethiopia, Tel: +2510916310331; Fax: +2510468811147; E-mail: mendemensa@gmail.com

Received May 07, 2016; Accepted June 29, 2016; Published June 30, 2016

Citation: Sorato MM, Tesfahun C, Lamessa D (2016) Levels and Predictors of Adherence to Self-care Behaviour among Adult Type 2 Diabetics at Arba Minch General Hospital, Southern Ethiopia. J Diabetes Metab 7: 684. doi:10.4172/2155 6156.1000684

Copyright: @ 2016 Sorato MM, et al. This is an open-access article distributed under the terms of the Creative Commons Attribution License, which permits unrestricted use, distribution, and reproduction in any medium, provided the original author and source are credited. 
American Diabetes Association (ADA) and American Association of Diabetes Educators (AADEs) yearly states optimal glycaemic control is achieved; when glycosylated haemoglobin (HbAlc) is less than $7 \%$ $[18,19]$. Successful diabetes care requires a systematic approach to supporting patients' behaviour changes, including 1) healthy lifestyle changes (physical activity, healthy eating, tobacco cessation, weight management, and effective coping), 2) disease self-management (taking and managing medication and, when clinically appropriate, selfmonitoring of glucose), and 3) prevention of diabetes complications (self-monitoring of foot health; active participation in screening for eye, foot, and renal complications; and immunizations) [20-22].

Lifestyle change strategies that combine diet, physical activity and behaviour modification are effective treatments for improving diabetic outcomes $[23,24]$; so that self-care behaviour adherence and patient education are the first steps in helping patients to better care and manage their disease $[25,26]$.

Diabetes reduces both quality of life and life expectancy and imposes large economic burdens on individuals and on national health care systems directly or indirectly [27-29]. Diabetes in sub-Saharan Africa greatly increased the risk of serious, costly complications including emotional distress, heart attack, stroke, kidney damage, blindness, neural damage leading to amputation, and reduced life expectancy [30].

Regardless of the type of diabetes; $95 \%$ of diabetes treatment relies on self-care behaviours and $95 \%$ of the self-care is usually provided by the patients or their families [31], hence diabetic patients must adjust their behaviour like making lifestyle changes to diet and physical activity levels and follow prescribed treatments to prevent diabetic complications, which may be potentially fatal, particularly for older individuals $[32,33]$. Hence It is important to examine and understand factors affecting self-management behaviours of diabetic patients but, about a third of the people suffering from diabetes may not be aware of it early considering the insidious onset and development $[34,35]$.

Study conducted on 256 Mexican American patients showed that good self-care associated with lower HbAlc levels [36-38], Study conducted in India showed that good practice associated with good glycaemic control [39] and similarly in Study conducted in Jimma university specialized hospital [40]. In study conducted in Tikur Anbessa Specialized Hospital revealed that 55.6\% respondents were adhered to diabetes Self-Management practices $[41,42]$. Study conducted in Dilla university referral Hospital, showed that male diabetic patients are two times more likely to have diet adjustment than females, and diabetic patients with very high income were 2.5 times more likely to have diet adjustment than with less income [25].

Self-monitoring of blood glucose (SMBG) is a tool that guides gycaemic management. Generally testing blood glucose before and after each meal and at bedtime over the course of 2-3 days per week is recommended [43]. The systematic review on Metabolic and Endocrine Disorders showed that the overall effect of SMBG was a statistically significant decrease of $0.39 \%$ in $\mathrm{HbA1c}$ [44].

Regular exercise has been shown to improve blood glucose control, reduce cardiovascular risk factors, contribute to weight loss and improve wellbeing. ADA recommends at least 150 minutes per week of moderate intensity aerobic physical activity that achieves $50-70 \%$ of maximal heart rate. Structured exercise interventions of at least 8 weeks duration have been shown to lower A1C by an average of $0.66 \%$ in people with type 2 diabetes even with no significant change in Body Mass Index [45].
According to the WHO, insufficient physical activity, defined as less than 150 minutes of moderate physical activity per week [or equivalent], was present in about a quarter of men and a third of women in African region [46,47]. A similar study done in Harari, Ethiopia, showed that only $31.1 \%$ had exercise for thirty minutes per day [48]. The WHO has reported that as many as $50 \%$ of the patients with chronic diseases do not take their medications as prescribed [49]. Hence Effective and successful glucose control requires appropriate and timely use of medication over the entire period of treatment, which is often lifelong [50].

The study conducted in Netherland showed apparent increase in the number of co-medications tends to decrease the adherence of patient with type-2 diabetes to their treatment regimens [51] and study conducted in south western Nigeria showed that Mean number of prescribed medications was $4.6 \pm 1.4$ [52]. Similar study conducted in North West Ethiopia showed that Self-reported adherence to medication measure by MMAS- 8 scale was low for $25.4 \%$ [49]. Study conducted in Kenyata National Hospital on 171 type 2 diabetes patients; showed that Most patients, 127 (74.3\% [53,54].

Positive family behaviors and parents encouraging and supporting youth in completing their own self-management may exert positive effects on diabetes $[55,56]$. Friends and families of individuals with diabetes play an important role in their well-being, successful selfmanagement, and achievement of in-range glycaemic control [57-59].

In a study conducted in Thailand, knowledge about the illness were significantly related with the level of self-care behaviors $[60,61]$. In study conducted in Nigeria to evaluate the level of knowledge among type 2 diabetics showed that knowledge is below mean score $39 \% \pm$ $16.7 \%$ [62]. In a South African primary care setting, showed lower levels of diabetes knowledge with an average of $52.2 \%$ compared to their Indian counterparts with an average of $75.9 \%[63,64]$.

Study conducted in Mekelle showed 132(44.0\%) respondents had good knowledge [65] and study conducted in Felege Hiwot Hospital that Half (49.8\%) had good knowledge and 144(36.8\%) participants had good practice on diabetes. Age group between 18-32 yrs was 6 times more likely to have good practice. Higher educational status was also associated with good knowledge and practice. Participants in grade 1-8, grade 9-12 and higher education and above were 3.5, 4.3 and 5.4 times respectively to have good practice [66].

Inadequate diabetic self-management remains a significant problem facing health care providers and populations in all settings. Patients who have adequate self-management have better outcomes, live longer, enjoy a higher quality of life, and suffer fewer symptoms and minimal complications [67]. Despite scientific support for glucose control as a therapeutic strategy in diabetes, many diabetics do not care enough of their disease, and this causes the lack of or imperfect control of glucose $[68,69]$. Several studies which have assessed and managed diabetes in different countries, all indicate that diabetes management in different societies, even in developed countries is not desirable [70]. Similarly Studies conducted in Different Hospitals in Ethiopia have shown that glycaemic control is poor [48].

Local evidences on diabetes knowledge, attitude, levels and predictors of self-care behaviour adherence and glycaemic control are limited in Arba Minch General Hospital. Factors influencing glycaemic control and adherence to self-care behaviour based on seven selfcare behaviour components have not been studied so far and Studies conducted elsewhere could not be used to infer about diabetic patients in the study area, as these differs in cultures and life style. 
Citation: Sorato MM, Tesfahun C, Lamessa D (2016) Levels and Predictors of Adherence to Self-care Behaviour among Adult Type 2 Diabetics at Arba Minch General Hospital, Southern Ethiopia. J Diabetes Metab 7: 684. doi:10.4172/2155-6156.1000684

Page 3 of 11

Therefore, to address these discrepancies, this research explored patient's diabetes knowledge, attitude, levels and predictors of adherence to self-care behaviour and glycaemic control, amongst adult type 2 diabetics and contribute to the scientific body of knowledge in general and it specifically provide necessary information for health care providers and diabetic patients in the Hospital for appropriate interventions to prevent or delay complications of DM. The study can be used as a basis for future similar studies at a diabetic follow-up unit at Arba Minch General Hospital.

\section{Objectives and research questions}

Research question: What are level and predictors of adherence to overall self-care behaviour in adult type 2 diabetics at Arba Minch General Hospital?

General objective: To asses Levels and Predictors of Adherence to Self-Care Behaviour among Adult Type 2 Diabetics at Arba Minch General Hospital, Southern Ethiopia.

\section{Specific objectives:}

- To determine level of adherence to self-care behaviour among adult type 2 diabetics at Arba Minch General Hospital.

- To identify Independent predictors of overall self-care behaviour adherence among adult type 2 diabetics at Arba Minch General Hospital.

\section{Methods and Materials}

\section{Study area and period}

This study was conducted from [ $15^{\text {th }}$-February to $15^{\text {th }}$-March, 2015] at Arba Minch Hospital, in Gamo Gofa zone; which is located about $505 \mathrm{~km}$ south from Addis Ababa, about $275 \mathrm{~km}$ from Hawassa, the capital of the SNNPR region. According to the 2007 census, Gamo Gofa Zone has a population of 1,595,570; of this 794,485 were male and 801,085 were female. There are three hospitals and 68 health centers offering health care services for the total population. Arba Minch Hospital is one of these hospitals and is located in Arba Minch Town. The hospital is rapidly expanding in terms of services it provides and infrastructures.

\section{Study design}

A facility-based cross sectional study was conducted amongst adult type 2 diabetic follow-up patients at Arba Minch General Hospital, Gamo Gofa Zone; Southern Ethiopia.

\section{Source and study population}

The source population were all type 2 diabetics who visit Arba Minch general hospital for diabetes follow-up care.

\section{Study population}

Study subjects included in this study were those aged 15 years and older, diagnosed with type 2 diabetes visited the hospital at the time of data collection period and fulfils eligibility criteria.

\section{Inclusion and exclusion criteria}

Inclusion criteria: Type 2 diabetic Patients who were 15 years and above having at least three month follow-up were included while Patients with a documented history of psychiatric illness; hearing impairement; serious health problems and pregnant women were excluded.

\section{Variables of the study}

Independent variables:

Socio-demographic variables: Sex, Age, Marital status, Religion, Ethnicity, Educational status, and Income.

- Age at diabetes onset

- Type of treatment

- Duration of diabetes

- Family history of diabetes

- Social drug use

- Presence of comorbidity

- History of hospitalization

- Patient physician relation

- Family support

- Knowledge of diabetes

- Attitude about diabetes

- Outcome variable: Adherence to self- care behaviour

\section{Sample size determination and sampling technique}

Sample size determination: The prevalence of glycaemic control and $17 \%$ prevalence was taken according to study conducted in Jimma University specialized Hospital [40] and Z value of 1.96 at $95 \%$ confidence interval was used and $10 \%$ was added for non-response rate.

The sample size was determined by using single population proportion and correction formulas. Formula for Correction for finite population was considered since the source population below 10,000.

$$
\text { no }=\left(\mathrm{z}^{2} \mathrm{pq}\right) / \mathrm{e}^{2}=216.8 \approx 217
$$

Corrected sample size $\approx 172$

Sampling technique and procedures: Consecutive sampling technique was used to collect data and patient coming to the clinic for a follow-up service during data collection period were interviewed after screening them for eligibility criteria on arrival. The questionnaire was asked to the patients as they move from registration, triage, meeting the clinician to exit with minimal interference with the clinic activities.

\section{Data collection tools and procedures}

Data collection tools: The Questionnaire contains five parts, Part I and II were used to collect socio demographic data and clinical status data of the study subjects. Patient professional relationship was determined by using validated tool [71]. Part III was used to collect medication adherence data by Morisky Medication Adherence Scale (MMAS) [72]. Part IV diabetes knowledge/DKT [73] and Part V diabetes attitude were validated for assessment of Diabetes attitude and knowledge respectively. Part VI is the modified SDSCA, which was used to measure seven areas or domains of diabetes self-care practices. Summary of diabetes self-care activities (SDSCA) is used to measure seven diabetes self-care activities [74].

\section{Data collection procedures}

Informed written consent was obtained from each patient at the time of their visit to the hospital. Anthropometric measurements were used to assess the body mass index (BMI) of the patients. Weights 
of patients were measured using weighing scale up to the nearest 100 g. Heights were measured using a standard height board with the participant wearing no shoes. Measurements for height were then taken to the nearest $1 \mathrm{~cm}$. The socio demographic data, disease related factors data, health system related data and data on diabetes knowledge, attitude, and self-care behaviours, and Patient professional relationship were collected by direct patient interview using structured and standardized questionnaires. The data were collected by trained (B.Sc.) nurses who have experience of data collection previously.

\section{Data quality control}

Questionnaires were prepared in English and translated into Amharic and translated back into English to check its consistency. The Amharic versions were used for data collection after pretesting on 5\% (9) of the actual sample size in Chencha Hospital diabetes clinic. Five (B.Sc.) nurses for data collection and one medical doctor (MD.) working in the hospital for supervision were given orientation before data collection. Continuous follow up and supervision was made by the principal investigator throughout the data collection period.

\section{Data analysis}

The collected data was checked for completeness and consistency by principal investigator on daily basis at the spot during the data collection time. Then data was transcribed back to English and entry was made using Epi-data 3.1 software and analysis was made using SPSS version 20.0. A summary descriptive statistics was computed for most variables; bivariate analysis was done to determine the presence of association between adherence to self-care behaviour with other variables [75-82]. To avoid many variables and unstable estimates in the subsequent model, only variables that reached a p-value less than 0.05 at bivariate analysis was kept in the subsequent model analysis. Multiple logistic regression analysis was applied to describe the functional independent predictors of adherence to self-care behaviour. A point estimates of Odds ratio (OR) with $95 \%$ confidence interval (CI) were determined to assess the strength of association between independent and dependent variables. For all statistical significant tests $\mathrm{p}$ - value $<0.05$ was used as a cut-off point.

\section{Ethical considerations}

Ethical clearance was obtained from institutional Review Board of Jimma University College of Public Health and Medical Sciences. Permission letters to conduct the study was obtained from, Gamo Gofa Zone, health department and Arba Minch General Hospital administration. Interview was carried out only with full consent of the patient being interviewed. Each respondent was assured that the information provided by him/ her was confidential and used only for the purpose of research. Respondents were allowed to refuse or discontinue participation at any time they want.

\section{Operational definitions and definition of terms}

- Age at disease onset: age when the patient is told by physician about the diagnosis for the first time or documentation of the age of the diagnosis at the first time.

- Being active: respondents were labelled to have optimal physical activity if he/she scores greater than or equal to $75 \%$, moderate if $50-75 \%$ and poor if less than $50 \%$ of the questionnaire.

- Dietary adherence: respondents were labeled to have "optimal dietary adherence" if they score $\geq 75 \%$ the mean score, "moderate" if they score $50-75 \%$ and "poor" if $<50 \%$ of the mean score of the total, on the closed ended questions related to dietary adherence.

- Family history of diabetes: having a history of diabetes of their parents and first- and second-levels of relatives as self-reported.

- Fasting blood glucose (FBS): blood is tested for glucose at least eight hours after meal.

Glycaemic control: The level of glycaemic control was indicated as 'adequate glycaemic control' when FBS results were between 70-130 $\mathrm{mg} / \mathrm{dL}(3.9-7.2 \mathrm{mmol} / \mathrm{L}$ ) (i.e. an average of three measures at different visits), or when RBS results were less than $180 \mathrm{mg} / \mathrm{dL}(10.0 \mathrm{mmol} / \mathrm{L})$; 'inadequate glycaemic control' takes place when FBS greater than 130 $\mathrm{mg} / \mathrm{dL}$ and RBS greater than $180 \mathrm{mg} / \mathrm{dL}$ [24].

- Good knowledge: Respondents were labelled to have good knowledge of diabetes if they scored greater than or equal to mean score of the total on the knowledge questions and otherwise poor knowledge.

- Good patient relation: Respondents were labelled to have good relationship if he/she scored greater than $80 \%$ of the questions related to patient professional relationship, moderate if $70-80 \%$ and poor if less than $70 \%$ were scored.

- Good self-care behaviour: Respondents were labeled to have "good self-care" if they score the mean score of the total or above, on the closed ended questions related to self-care behaviour and poor otherwise.

- Health coping: Respondents were labeled to have "optimal health coping" if they score $\geq 75 \%$ the mean score, "moderate" if they score $50-75 \%$ and "poor" if $<50 \%$ of the mean score of the total, on the closed ended questions related to health coping.

- Hypoglycaemia: An abnormally diminished concentration of glucose in the blood $<70 \mathrm{mg} / \mathrm{dl}$.

Medication adherence: The degree of adherence was determined by using MMAS-8 and participants scoring (1-2) were recorded as good adherence and those ( $\geq 3$ points) were recorded as poor adherence [75].

Monthly income: Defined as all household's total monthly income that participants self-reported and categorized as low if less than 750.00 birr and high otherwise.

Positive attitude: Respondents were labelled to have positive attitude if they scored $50 \%$ or above to questions related to attitude; otherwise, negative attitude.

Problem solving: respondents were labeled to have "optimal problem solving" if they score $\geq 75 \%$ the mean score, "moderate" if they score $50-75 \%$ and "poor" if $<50 \%$ of the mean score of the total, on the closed ended questions related to problem solving.

Risk reduction: respondents were labeled to have "optimal risk reduction" if they score $\geq 75 \%$ the mean score, moderate if they score $50-75 \%$ and poor if $<50 \%$ of the mean score of the total, on the closed ended questions related to risk reduction.

Self-care behaviours mean score: (Number of days patient practiced specific behaviour )/(Total number of days under questions designed for that behaviour).

Self-care: It is the practice of activities that individual diabetics will 
initiate and perform on their own behalf in controlling their disease, maintaining life, health and wellbeing.

Self-monitoring of blood glucose: Respondents were labeled to have "optimal self-monitoring" if they score $\geq 75 \%$ the mean score, "moderate" if they score $50-75 \%$ and "poor" if $<50 \%$ of the mean score of the total, on the closed ended questions related to self-monitoring of blood glucose.

\section{Results}

Socio-demographic characteristics of the respondents: One hundred ninty four type 2 diabetics were included in this study. With regard to Sex distribution 99 (51.0\%) were Females. The majority of study participants $115(59.3 \%)$ were in the age group of 35-54 years and mean age ( \pm standard deviation (SD)) of participants was $50.3( \pm 13.2)$ years, ranging from 17-83 years. One hundred one (52.1\%) were orthodox by religion and majority of the respondents 102 (52.6\%) were Gamo by ethnicity. One third (29.4\%) of respondents had monthly income below 750.00 birr per month) with mean monthly income of $1872.55 \pm 1351.16$ birr ranging from $300-8,000$ birr. With regard to educational status of respondents 57 (29.4\%) were attended college and above followed by 1-8 grade 54 (27.8\%) (Table 1).

Diabetes related clinical characteristics: Majority of respondents $114(58.7 \%)$ reported that there diabetes was diagnosed at age of 35-54 years with mean age of diagnosis $( \pm \mathrm{SD}) 45.29( \pm 12.8)$ years ranging from 15-77 years. More than half of respondents 111 (57.2\%) had diabetes duration less than five years, with mean duration of diabetes $5.02 \pm 3.8$ years, ranging from $1-20$ years. Most of patients $169(87.1 \%)$ were on oral anti diabetics for their diabetes management and the mean number of drugs per patient for treatment was $2.09 \pm 0.5$. Most of respondents $129(66.5 \%)$ had no family history of diabetes and majority of patients $165(85.1 \%$ ) had family support for their diabetes care. Eighty seven $(44.8 \%)$ had good glycaemic control and mean, fasting blood glucose of $148.8 \mathrm{mg} / \mathrm{dl} \pm 48.7 \mathrm{mg} / \mathrm{dl}$, ranging from 87.5 $449 \mathrm{mg} / \mathrm{dl}$ and Majority of respondents $168(86.6 \%)$ had no history of hospitalization due to hyperglycaemia (Table 2).

Most of patients $169(87.1 \%)$ were on oral anti diabetics for their diabetes management followed by insulin 14(7.21\%) (Figure 1). With regard to presence of comorbidity along with diabetes; only $36(18.6 \%)$ of respondents had comorbidity, among which hypertension was the most common 24(69.4\%) followed by heart failure and kidney disease (Figure 2).

Diabetes and health facility related factors: Majority $169(87.1 \%)$ of respondents had good relationship with professionals caring for their diabetes and only 13(6.7\%) respondents had poor relationship with health professionals caring for their diabetes (Figure 3).

Diabetes knowledge: One hundred eighty six (95.8\%), subjects had good knowledge and only $4.2 \%$ had poor knowledge about diabetes and its care principles. Participants were asked about causes, types and management principles of diabetes, accordingly, 194(100\%), responded that Cuts and abrasions on diabetics heal more slowly; 190(97.9\%), said that A fasting blood sugar level of 210 is too high; $165(85.05 \%)$, reported that Eating too much sugar and other sweet foods is a cause of diabetes, In untreated diabetes, the amount of sugar in the blood usually increases, If I am diabetic, my children have a higher chance of being diabetic and diabetes is not curable (Table 3 ).

Diabetes attitude: One hundred sixteen (59.8\%) of respondents had positive attitude towards diabetes. As per reported by respondents $94(48.5 \%)$ were afraid of their condition and said it was difficult to believe they were suffering from diabetes, $78(40.2 \%)$ felt unhappy and depressed because of the diabetes, 105(54.1\%) felt satisfied with their life and $165(85.1 \%)$ felt they could do anything that they set out to do concerning their diabetes and 32(42.7\%) found it hard to carry out all the practices related to the disease. However, 194(100\%) stated that, all things considered, they were very well right now (Table 4).

Adherence to self-care behaviour: This study revealed both individual and overall adherence to self-care behaviour. Majority $169(87.1 \%)$ of respondents practiced health coping behaviour (i.e. managing stress related to diabetes), 163(84.0\%) adhered to medication taking behaviour and 116(59.8\%) practiced recommended dietary behaviour. On the other hand, only $19(9.8 \%)$ and $11(5.7 \%)$ practiced problem solving and self-monitoring of blood glucose respectively.

\begin{tabular}{|c|c|}
\hline Socio-demographic characteristics & Number (\%) \\
\hline \multicolumn{2}{|l|}{ Sex } \\
\hline Female & $99(51.0)$ \\
\hline Male & $95(49.0)$ \\
\hline \multicolumn{2}{|l|}{ Age } \\
\hline $15-24$ & $8(4.1)$ \\
\hline $25-34$ & $4(2.1)$ \\
\hline $35-44$ & $55(28.4)$ \\
\hline $45-54$ & $60(30.9)$ \\
\hline $55-64$ & $38(19.6)$ \\
\hline Above 64 & $29(14.9)$ \\
\hline \multicolumn{2}{|l|}{ Religion } \\
\hline Orthodox & $101(52.1)$ \\
\hline Protestant & $66(34.0)$ \\
\hline Muslim & $22(11.3)$ \\
\hline Catholic & $5(2.6)$ \\
\hline \multicolumn{2}{|l|}{ Ethnicity } \\
\hline Gamo & $100(51.5)$ \\
\hline Amhara & $41(21.1)$ \\
\hline Gofa & $27(13.9)$ \\
\hline Wolayta & $19(9.8)$ \\
\hline Others* & $7(3.6)$ \\
\hline \multicolumn{2}{|l|}{ Marital status } \\
\hline Married & $157(80.9)$ \\
\hline Divorced & $17(8.8)$ \\
\hline Widowed & 12(6.2) \\
\hline Single & $8(4.1)$ \\
\hline \multicolumn{2}{|l|}{ Monthly income } \\
\hline$\geq 750.00$ birr & $137(70.6)$ \\
\hline$<750.00$ birr & $57(29.4)$ \\
\hline \multicolumn{2}{|l|}{ Educational status of respondent } \\
\hline College and above & $57(29.4)$ \\
\hline 1-8 grade & $54(27.8)$ \\
\hline $9-12$ grade & $51(26.3)$ \\
\hline Illiterate & $32(16.5)$ \\
\hline \multicolumn{2}{|l|}{ Occupational status } \\
\hline Merchant & $57(29.4)$ \\
\hline Gov't/private employee & $48(24.7)$ \\
\hline Farmer & $45(23.2)$ \\
\hline House wife & $22(11.3)$ \\
\hline Retired & $13(6.7)$ \\
\hline Daily laborer & $9(4.6)$ \\
\hline
\end{tabular}

*Gurage, Tigre, Hadiya, Kambata, Konso, Zayise

Table 1: Socio-demographic characteristics of respondents among adults type 2 diabetics, in Arba Minch General Hospital, Southern Ethiopia, March $2015(n=194)$. 
Citation: Sorato MM, Tesfahun C, Lamessa D (2016) Levels and Predictors of Adherence to Self-care Behaviour among Adult Type 2 Diabetics at Arba Minch General Hospital, Southern Ethiopia. J Diabetes Metab 7: 684. doi:10.4172/2155-6156.1000684

Page 6 of 11

\begin{tabular}{|c|c|}
\hline Clinical and social factors & Number (\%) \\
\hline \multicolumn{2}{|l|}{ Age at disease on set } \\
\hline $15-24$ & $8(4.1)$ \\
\hline $25-34$ & $28(14.4)$ \\
\hline $35-44$ & $59(30.4)$ \\
\hline $45-54$ & $55(28.4)$ \\
\hline $55-64$ & $27(13.9)$ \\
\hline Above 64 & $17(8.8)$ \\
\hline \multicolumn{2}{|c|}{ Duration of diabetes in years $(n=194)$} \\
\hline$\leq 5$ & 122(62.9) \\
\hline $6-10$ & $54(27.8)$ \\
\hline $11-15$ & $15(7.7)$ \\
\hline Above 15 & $3(1.5)$ \\
\hline \multicolumn{2}{|l|}{ Number of medications } \\
\hline Two & 144(74.2) \\
\hline Three and above & $34(17.5)$ \\
\hline One & $16(8.2)$ \\
\hline \multicolumn{2}{|c|}{ Frequency of administration per day } \\
\hline Two & $160(82.5)$ \\
\hline Three & $29(14.9)$ \\
\hline One & $5(2.6)$ \\
\hline \multicolumn{2}{|l|}{ Family history of diabetes } \\
\hline No relative & $129(66.5)$ \\
\hline $1^{\text {st }}$ degree relative & $51(26.3)$ \\
\hline $2^{\text {nd }}$ degree relative & $14(7.2)$ \\
\hline \multicolumn{2}{|l|}{ Family support for diabetes care } \\
\hline Always supporting & 166(85.6) \\
\hline Sometimes supporting & $28(14.4)$ \\
\hline \multicolumn{2}{|l|}{ Alcohol use status } \\
\hline Ex-drinker & 146(75.3) \\
\hline Non-drinker & $36(18.6)$ \\
\hline Drinker & $12(6.2)$ \\
\hline \multicolumn{2}{|l|}{ Chat use } \\
\hline Non-chewer & 174(89.7) \\
\hline Ex-chewer & $15(7.7)$ \\
\hline Chewer & $5(2.6)$ \\
\hline \multicolumn{2}{|l|}{ Smoking status } \\
\hline Non-smoker & 189(97.4) \\
\hline Ex-smoker & $5(2.6)$ \\
\hline \multicolumn{2}{|l|}{ Average fasting blood sugar } \\
\hline$>130 \mathrm{mg} / \mathrm{dl}$ & 107(55.2) \\
\hline $70-130 \mathrm{mg} / \mathrm{dl}$ & $87(44.8)$ \\
\hline \multicolumn{2}{|l|}{ Body mass index } \\
\hline $17.9-24.9 \mathrm{~kg} / \mathrm{m}^{2}$ & $116(59.8)$ \\
\hline $25-30 \mathrm{~kg} / \mathrm{m}^{2}$ & $67(34.5)$ \\
\hline Above $30 \mathrm{~kg} / \mathrm{m}^{2}$ & $11(5.7)$ \\
\hline \multicolumn{2}{|c|}{ History of hospitalization related to diabetes } \\
\hline Not hospitalized & 168(86.6) \\
\hline Hospitalized & $26(13.4)$ \\
\hline \multicolumn{2}{|c|}{$\begin{array}{c}\text { Experience of hypoglycaemia in past one } \\
\text { year }\end{array}$} \\
\hline Not experienced & $165(85.1)$ \\
\hline Experienced & $28(14.4)$ \\
\hline I don't know & $1(0.5)$ \\
\hline \multicolumn{2}{|l|}{ Presence of comorbidities } \\
\hline No & 158(81.4) \\
\hline Yes & $36(18.6)$ \\
\hline
\end{tabular}

Table 2: Clinical characteristics respondents among adults type 2 diabetics, in Arba Minch General Hospital, Southern Ethiopia, March $2015(\mathrm{n}=194)$.
With regard to physical activity 98(50.5\%) of respondents reported to have optimal to moderate physical activity (participated in at least 30 minutes of physical activity for total of $\geq 3$ days per week) and 96(49.5\%) of participants were least active. On the other hand majority of patients reported having their serum glucose measured at least once or twice a month usually on day of their clinic appointments and only $16(8.2 \%)$ of respondents had self-monitoring of their blood glucose at home.

This study also revealed that only 76(39.1\%) respondents reported to have optimal risk reduction behaviour practice (checking their foot, inspecting inside of shoes and visiting eye and dental clinic).

Overall self-care behaviour adherence above half 114(58.8\%) had

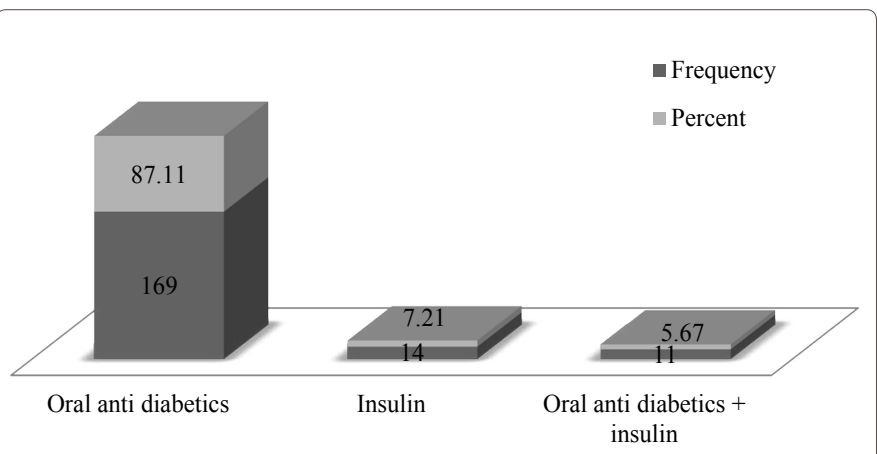

Figure 1: Diabetes management type among adult type 2 diabetic patients at Diabetes follow-up clinic among adults type 2 diabetics, in Arba Minch General Hospital, Southern Ethiopia, March $2015(n=194)$.

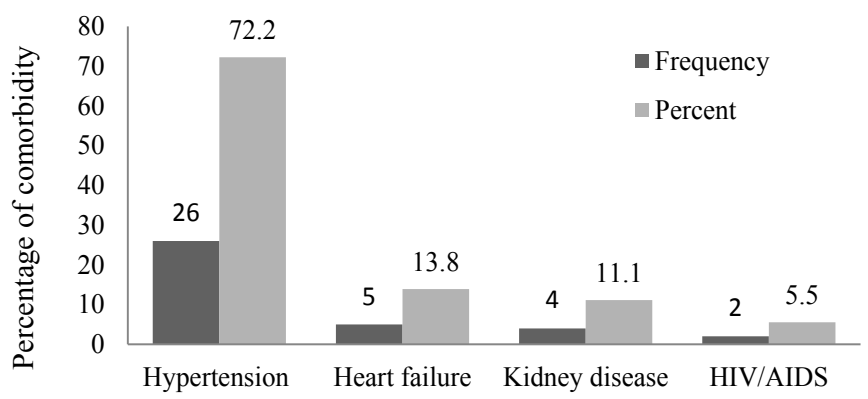

Figure 2: Type of comorbidities among adult type 2 diabetic patients at Diabetes follow-up clinic among adults type 2 diabetics, in Arba Minch General Hospital, Southern Ethiopia, March $2015(n=36)$.

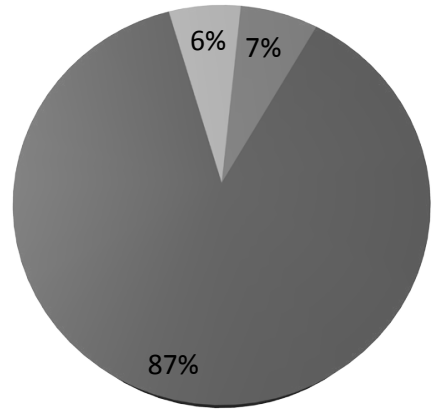

- Good relationship

Moderate relationship

- Poor relationship

Figure 3: Patient professional relationship at Diabetes follow-up clinic among adults type 2 diabetics, in Arba Minch General Hospital, Southern Ethiopia March $2015(n=194)$. 
Citation: Sorato MM, Tesfahun C, Lamessa D (2016) Levels and Predictors of Adherence to Self-care Behaviour among Adult Type 2 Diabetics at Arba Minch General Hospital, Southern Ethiopia. J Diabetes Metab 7: 684. doi:10.4172/2155-6156.1000684

Page 7 of 11

\begin{tabular}{|c|c|c|c|c|}
\hline \multirow{2}{*}{ Diabetes knowledge response } & \multicolumn{4}{|c|}{ Response } \\
\hline & Correct & $\%$ & Incorrect & $\%$ \\
\hline $\begin{array}{l}\text { Cuts and abrasions on diabetics heal more } \\
\text { slowly. }\end{array}$ & 194 & 100 & 0 & 0 \\
\hline $\begin{array}{l}\text { Diabetics should take extra care when cutting } \\
\text { their toe nails. }\end{array}$ & 194 & 100 & 0 & 0 \\
\hline A fasting blood sugar level of 210 is too high. & 190 & 97.93 & 4 & 2.06 \\
\hline $\begin{array}{l}\text { Tight elastic hose or socks are not bad for } \\
\text { diabetics. }\end{array}$ & 186 & 95.87 & 8 & 4.12 \\
\hline Diabetes can damage my kidneys. & 180 & 92.78 & 14 & 7.21 \\
\hline $\begin{array}{l}\text { The way I prepare my food is as important as } \\
\text { the foods I eat. }\end{array}$ & 175 & 90.20 & 19 & 9.79 \\
\hline $\begin{array}{l}\text { Eating too much sugar and other sweet foods } \\
\text { is a cause of diabetes. }\end{array}$ & 165 & 85.05 & 29 & 14.94 \\
\hline $\begin{array}{l}\text { In untreated diabetes, the amount of sugar in } \\
\text { the blood usually increases. }\end{array}$ & 165 & 85.05 & 29 & 14.94 \\
\hline $\begin{array}{l}\text { If I am diabetic, my children have a higher } \\
\text { chance of being diabetic. }\end{array}$ & 165 & 85.05 & 29 & 14.94 \\
\hline Diabetes can be cured. & 165 & 85.05 & 29 & 14.94 \\
\hline $\begin{array}{l}\text { There are two main types of diabetes: Type } \\
\text { 1and Type } 2 \text {. }\end{array}$ & 165 & 85.05 & 29 & 14.94 \\
\hline $\begin{array}{l}\text { A person with diabetes should cleanse a cut } \\
\text { with iodine and alcohol. }\end{array}$ & 145 & 74.74 & 49 & 25.25 \\
\hline $\begin{array}{l}\text { Diabetes can cause loss of feeling in my } \\
\text { hands, fingers, and feet. }\end{array}$ & 145 & 74.74 & 49 & 25.25 \\
\hline A diabetic diet consists mostly of special foods. & 145 & 74.74 & 49 & 25.25 \\
\hline Diabetes often causes poor circulation. & 123 & 63.40 & 71 & 36.59 \\
\hline $\begin{array}{l}\text { The usual cause of diabetes is lack of effective } \\
\text { insulin in the body. }\end{array}$ & 112 & 57.73 & 82 & 42.26 \\
\hline $\begin{array}{l}\text { Frequent urination and thirst are signs of low } \\
\text { blood sugar. }\end{array}$ & 112 & 57.73 & 82 & 42.26 \\
\hline $\begin{array}{l}\text { Shaking and sweating are signs of high blood } \\
\text { sugar. }\end{array}$ & 104 & 53.60 & 90 & 46.39 \\
\hline $\begin{array}{l}\text { Medication is more important than diet and } \\
\text { exercise to control my diabetes. }\end{array}$ & 102 & 52.57 & 92 & 47.42 \\
\hline $\begin{array}{l}\text { The best way to check my diabetes is by } \\
\text { testing my urine. }\end{array}$ & 100 & 51.54 & 94 & 48.45 \\
\hline Kidneys produce insulin & 98 & 50.51 & 96 & 49.48 \\
\hline $\begin{array}{l}\text { Regular exercise will increase the need for } \\
\text { insulin or other diabetic medication. }\end{array}$ & 98 & 50.51 & 96 & 49.48 \\
\hline An insulin reaction is caused by too much food. & 54 & 27.83 & 140 & 72.16 \\
\hline $\begin{array}{l}\text { Diabetes is caused by failure of the kidneys to } \\
\text { keep sugar out of the urine. }\end{array}$ & 40 & 20.61 & 154 & 79.38 \\
\hline
\end{tabular}

Table 3: Frequency distribution of diabetic patients' knowledge response among adults type 2 diabetics, in Arba Minch General Hospital, Southern Ethiopia, March $2015(n=194)$

poor self-care behaviour adherence and only $80(41.2 \%)$ practiced the recommended self-care practices.

Medication adherence based on MMAS-8: Most of respondents $163(84.0 \%)$ had good medication adherence and only $31(15.9 \%)$ of respondents had poor adherence. The major reason for not adhering to medication was forgetting to take medications $14(45.2 \%)$ followed by failure to understand instructions $8(25.8 \%)$ (Figure 4$)$.

Predictors of adherence to self-care behaviour: Multivariable logistic regression analysis was done to identify independent predictors of adherence to self-care behaviour among the study participants. Respondents aged 35-44 were 13.4 times more likely to practice self-care activities as compared to those above the age of 64 years, $[\mathrm{AOR}=13.403,95 \% \mathrm{CI}=1.582,113.564]$, Respondents earning $<750.00$ birr per month were less likely $[\mathrm{AOR}=0.340,95 \% \mathrm{CI}=0.119,0.976]$ to have good adherence to self-care behaviour than those earning greater than $\geq 750.00$ birr and individuals with diabetes onset age between 15-24 years were 11.3 times [AOR $=11.3,95 \% \mathrm{CI}=2.621,49.065]$ and between 25-34 years were 7.5 times [AOR=7.5, 95\% CI=2.0081, 28.23] more likely to have adherence to self-care behaviour than those above 64 years (Tables 5 and 6 ).

\section{Discussion}

\section{Predictors of adherence to self-care behaviour}

Diabetes self-care is an essential component of diabetes care. Diabetes self-management strategies increase lifestyle adjustments to maintain best possible diabetes management to achieve optimal glycaemic control in type 2 diabetics [83-91]. In this study the current situation of adherence to self-care behaviour of type 2 diabetics in Arba Minch General Hospital and factors that contribute to efficient adherence to self-care behaviour of diabetics was investigated.

In this study only $80(41.2 \%)$ practiced the recommended self-care behaviour activities. The finding of this study was similar to study done in Harari $39.3 \%$ of the study participants had good self-care practices [48]. However findings from study done in JUSH; $45 \%$ of the participants had Good self-care practice [40] and Nekemte Referral Hospital showed that; $45 \%$ of study participants had good self-care practices [9]. This variation could be due to difference in glycaemic target range used, instruments used to access self-care behaviour adherence since previous studies have used old AADEs criteria while we used new AADEs criteria.

\begin{tabular}{|l|c|c|c|c|}
\hline \multirow{2}{*}{ Diabetes Attitude questions } & \multicolumn{4}{|c|}{ Response } \\
\cline { 2 - 5 } & Positive & $\%$ & Negative & $\%$ \\
\hline I'm afraid of my diabetes & 100 & 51.54 & 94 & 48.45 \\
\hline $\begin{array}{l}\text { I find it hard to believe that I really have } \\
\text { diabetes }\end{array}$ & 100 & 51.54 & 94 & 48.45 \\
\hline $\begin{array}{l}\text { I feel unhappy and depressed because of } \\
\text { my diabetes }\end{array}$ & 116 & 59.79 & 78 & 40.20 \\
\hline $\begin{array}{l}\text { I feel I'm not as good as others because of } \\
\text { my diabetes }\end{array}$ & 120 & 61.85 & 74 & 38.14 \\
\hline $\begin{array}{l}\text { I find it hard to do all the things I have to do } \\
\text { for my diabetes }\end{array}$ & 150 & 77.31 & 44 & 22.68 \\
\hline \begin{tabular}{l} 
I feel satisfied with my life \\
\hline I can do just about anything I set out to do
\end{tabular} & 105 & 54.12 & 89 & 45.87 \\
\hline Diabetes doesn't affect my life at all & 60 & 30.92 & 34 & 69.07 \\
\hline $\begin{array}{l}\text { I am pretty well off, all things considered } \\
\text { Things are going very well for me right now }\end{array}$ & 130 & 67.01 & 64 & 32.98 \\
\hline
\end{tabular}

Note: The answer to the question was recorded as positive for the first 5 questions if the respondents answered them No since they are questions of negative nature and for the next 5 questions, recorded as positive if they answered them Yes since they are questions of positive nature.

Table 4: Frequency distribution of patients' diabetes Attitude response among adults type 2 diabetics, in Arba Minch General Hospital, Southern Ethiopia, March $2015(n=194)$

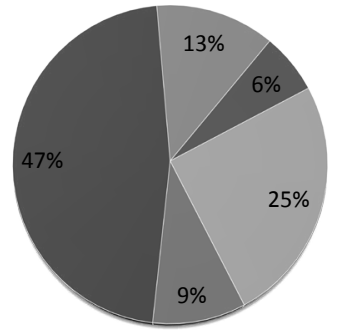

Medication is expensive

E Does not understand instructions

Prefers not to take

- Forgets to take

- Medication is not available

Figure 4: Reasons for not taking Medication among adults type 2 diabetics, in Arba Minch General Hospital, Southern Ethiopia, March 2015 ( $n=194)$. 
Citation: Sorato MM, Tesfahun C, Lamessa D (2016) Levels and Predictors of Adherence to Self-care Behaviour among Adult Type 2 Diabetics at Arba Minch General Hospital, Southern Ethiopia. J Diabetes Metab 7: 684. doi:10.4172/2155-6156.1000684

Page 8 of 11

\begin{tabular}{|c|c|c|c|}
\hline \multicolumn{2}{|c|}{ Self-care behaviour components } & \multirow{2}{*}{$\begin{array}{c}\text { Number (\%) } \\
116(59.7) \\
\end{array}$} & \multirow{2}{*}{$\begin{array}{c}\text { Mean } \pm \text { SD } \\
0.903 \pm 0.06679\end{array}$} \\
\hline \multirow{3}{*}{ Dietary adherence } & Optimal dietary adherence & & \\
\hline & Moderate dietary adherence & $44(22.6)$ & $0.6473 \pm 0.0763$ \\
\hline & Poor dietary adherence & $34(17.6)$ & $0.3824 \pm 0.04943$ \\
\hline \multirow{3}{*}{ Physical activity } & Optimal physical activity & $78(40.2)$ & $0.9355 \pm 0.06679$ \\
\hline & Moderate physical activity & $20(10.3)$ & $0.6256 \pm 0.0693$ \\
\hline & Poor physical activity & $96(49.5)$ & $0.3653 \pm 0.0566$ \\
\hline \multirow{3}{*}{ Self-blood glucose monitoring } & Optimal self-monitoring & $5(2.5)$ & $0.7149 \pm 0.02208$ \\
\hline & Moderate self-monitoring & $11(5.6)$ & $0.5844 \pm 0.0771$ \\
\hline & Poor self-monitoring & $178(91.7)$ & $0.2512 \pm 0.09337$ \\
\hline \multirow{2}{*}{ Medication taking } & Optimal medication taking & 188(96.9) & $0.9686 \pm 0.04903$ \\
\hline & Poor medication taking & $6(3.1)$ & $0.6429 \pm 0.04994$ \\
\hline \multirow{3}{*}{ Risk reduction } & Optimal risk reduction & $59(30.4)$ & $0.9531 \pm 0.04526$ \\
\hline & Moderate risk reduction & $17(8.7)$ & $0.6587 \pm 0.051$ \\
\hline & Poor risk reduction & $118(60.8)$ & $0.38 \pm 0.036$ \\
\hline \multirow{3}{*}{ Health coping } & Optimal health coping & $169(87.1)$ & $0.9007 \pm 0.0506$ \\
\hline & Moderate health coping & $12(6.2)$ & $0.5893 \pm 0.06186$ \\
\hline & Poor health coping & 13(6.7) & $0.3736 \pm 0.05943$ \\
\hline \multirow{3}{*}{ Problem solving } & Optimal problem solving & $47(24.2)$ & $0.9688 \pm 0.06156$ \\
\hline & Moderate problem solving & 19(9.8) & $0.6190 \pm 0.0693$ \\
\hline & Poor problem solving & $128(66)$ & $0.167 \pm 0.06960$ \\
\hline
\end{tabular}

All self-care practices were divided into three categories based on the following (below $0.5=$ poor, $0.5-0.75=$ moderate, and $0.75-1=$ optimal) except for medication taking practice $0-0.75=$ poor and $0.75-1=$ optimal.

Self care behaviors mean score $=\frac{\text { Number of days patient practiced specific behavior }}{\text { Total number of days under questions designed for that behavior }}$

Table 5: Diabetes patients' self-care behaviour components among adults type 2 diabetics, in Arba Minch General Hospital, Southern Ethiopia, March 2015 ( $n=194$ ).

\begin{tabular}{|c|c|c|c|c|c|c|c|c|c|c|c|}
\hline \multirow{3}{*}{\multicolumn{3}{|c|}{ Adherence to self-care behaviour ${ }^{\text {a }}$}} & \multicolumn{2}{|c|}{ Self-care behaviour } & \multirow{3}{*}{ COR } & \multirow{2}{*}{\multicolumn{2}{|c|}{$95 \% \mathrm{Cl}$ COR }} & \multirow[b]{3}{*}{ AOR } & \multirow{2}{*}{\multicolumn{2}{|c|}{$95 \% \mathrm{Cl}$ for AOR }} & \multirow{3}{*}{$P$ value } \\
\hline & & & \multirow{2}{*}{$\begin{array}{c}\text { Optimal } \\
\text { N (\%) }\end{array}$} & \multirow{2}{*}{$\begin{array}{l}\text { Poor } \\
\text { N (\%) }\end{array}$} & & & & & & & \\
\hline & & & & & & Lower bound & Upper bound & & $\begin{array}{l}\text { Lower } \\
\text { bound }\end{array}$ & Upper bound & \\
\hline \multirow{14}{*}{$\begin{array}{c}\text { Optimal } \\
\text { adherence } \\
\text { to self-care } \\
\text { behaviour }\end{array}$} & \multirow{6}{*}{$\begin{array}{l}\text { Age of the } \\
\text { patient }\end{array}$} & $15-24$ & 0 & $8(100)$ & 0.462 & 0.013 & 16.088 & 0.493 & 0.033 & 7.306 & 0.607 \\
\hline & & $25-34$ & 1(33.3) & $3(66.7)$ & 0.955 & 0.085 & 10.710 & 1.652 & 0.076 & 35.802 & 0.749 \\
\hline & & $35-44$ & $52(94.5)$ & $3(5.5)$ & 5.727 & 0.004 & 0.078 & 13.403 & 1.582 & 113.564 & $0.017^{*}$ \\
\hline & & $45-54$ & $18(30)$ & $42(70)$ & 0.742 & 0.269 & 2.047 & 1.839 & 0.374 & 9.040 & 0.453 \\
\hline & & $55-64$ & $2(5.2)$ & $36(94.8)$ & 0.018 & 1.091 & 30.078 & 0.033 & 0.005 & 0.223 & $0.000^{*}$ \\
\hline & & Above 64 (Ref) & $7(24.1)$ & $22(85.9)$ & 1 & & & 1 & & & \\
\hline & \multirow{2}{*}{$\begin{array}{l}\text { Monthly } \\
\text { income }\end{array}$} & $<750.00$ & $13(22.8)$ & $44(77.2)$ & 3.240 & 1.603 & 6.547 & 0.340 & 0.119 & 0.976 & $0.045^{*}$ \\
\hline & & $\geq 750.00$ (Ref) & $67(48.9)$ & $70(51.1)$ & 1 & & & 1 & & & \\
\hline & \multirow{6}{*}{$\begin{array}{l}\text { Age at onset } \\
\text { of diabetes }\end{array}$} & $15-24$ & 0 & $8(100)$ & 0.041 & 0.001 & 2.227 & 11.339 & 2.621 & 49.065 & $0.001^{*}$ \\
\hline & & $25-34$ & $22(78.5)$ & $6(21.5)$ & 0.084 & 0.020 & 0.354 & 7.530 & 2.008 & 28.233 & $0.003^{*}$ \\
\hline & & $35-44$ & $45(76.3)$ & $14(23.7)$ & 2.462 & 0.476 & 12.716 & .320 & .076 & 1.355 & 0.122 \\
\hline & & $45-54$ & $6(10.9)$ & $49(89.1)$ & 2.513 & 0.616 & 10.243 & .369 & .070 & 1.954 & 0.241 \\
\hline & & $55-64$ & $3(11.1)$ & $24(88.9)$ & 0.096 & 0.027 & 0.341 & . & . & . & . \\
\hline & & Above 64 (Ref) & $4(23.5)$ & $13((76.5)$ & 1 & & & 1 & & & \\
\hline
\end{tabular}

a. The reference category is: Poor adherence to self-care behaviour.

*Statistically significant at $\mathrm{p}<0.05$

Table 6: Multivariable logistic regression of Predictors of adherence to self-care behaviour predicting the likelihood of self-care behaviour adherence among adults type 2 diabetics, in Arba Minch General Hospital, Southern Ethiopia, March 2015, $(n=194)$.

There is no statistically significant association between educational level and good adherence self-care behaviour. This is incomparable with systematic review, showed that there is a positive correlation between education and regular diabetic self-care [91]. High educational attainment was associated with good and regular Type 2 DM self-care and it was also discovered that higher educational attainment were associated with less dependence on medications, high level of physical activity, and SMBG regularly and were associated with positive support behaviour or attitude [90].

This study showed that respondents aged 35-44 years were 13.4 times $[\mathrm{AOR}=13.4,95 \% \mathrm{CI}=1.582,113.564]$ more likely to have good adherence to self-care behaviour than those above the age of 64 years. This study is similar to study done in Nekemte Referral hospital, respondents in age group 35-44 were more likely perform self-care as 
compared to those above the age of sixty five $[9,48]$ and study done in JUSH, age is associated with self-care practices [40], study conducted in Thailand, age was an independent predictor of self-care practices [60] being young aged in Type $2 \mathrm{DM}$ was associated with ability to shifting of view or mentality and motivation to engage in healthy lifestyles [91]. This could be attributed to lack of motivation and lack of social support in elderly individuals compared to young adults.

Respondents earning $<750.00$ birr per month were less likely $[\mathrm{AOR}=0.340,95 \% \mathrm{CI}=0.119,0.976]$ to have good adherence to selfcare behaviour than those earning greater than $\geq 750.00$ birr. This is similar with study done in Nekemte Referral Hospital; Subjects earning relatively high average monthly income (750-1050) Birr were 5.6 times more likely to practice self-care than those earning less than 350 Birr [9] and study done in Harari; patients relatively in high income category can get healthy foods that are recommended for diabetic patients [48], high income was correlated with high self-care ability or low income was associated with low self-care ability than those middle and high income patients [91].

About one half of the study population 96(49.5\%) reported typical activities of daily living as regular exercise and only small proportion 76(40\%) did additional activities purely for exercise. This is lower than the current recommendation made by ADA which states that adults with diabetes should be advised to perform at least $150 \mathrm{~min} /$ week of moderate-intensity aerobic physical activity (50-70\% of maximum heart rate), spread over at least 3 days/week with no more than 2 consecutive days without exercise [24]. This might be due to lack knowledge on difference between physical activity and daily living activities and lack of access to recreational centers in the area.

In this study there was no statistically significant association between Diabetes Attitude and good adherence to self-care behaviour. This is in contrast to study conducted in Dilla University referral hospital showed that; individuals who had positive perception towards diabetes were 2.7 times more likely to perform recommended self-care than negative perception [25]. Similarly a study conducted in JUSH; Patients with high perceived severity of the disease was more likely to adhere to self-care practice [40]. This variation could be explained by difference in socio-economic characteristics, hospital setting and instruments used.

\section{Limitations of the Study}

The results of this study should be interpreted in light of its limitations. The adherence to self-care behaviours of the study participants were based on self-reports and possibility of desirability bias. Mean fasting blood sugar of the last three months nearest to study period rather than glycosylated haemoglobin to determine the level of glycaemic control was used, being single-centered study inferences should be made with caution and the use of cross-sectional data that can only demonstrate an association and not causality.

\section{Conclusion and Recommendations}

\section{Conclusion}

This study revealed that; adherence to self-care behaviour particularly physical activity, self-monitoring of blood glucose; problem solving and glycaemic control of adult type 2 diabetics were low. In this study respondents had high level of knowledge on diabetes and its care principles but inappropriate self-care practices. The respondents' age, age at onset of diabetes, monthly income and age at diagnosis of diabetes as independent predictors for adherence to selfcare behaviour.

\section{Recommendation}

The following recommendations were made as per results of this study to improve the situation of diabetic patients:

1. Regional Health Bureau and Zonal Health Department in coordination with Arba Minch Hospital Diabetic Association Coordinators should have to develop health information dissemination programmes and strategies to improve the awareness of diabetic patients about the importance of glycaemic control and self-care practices especially physical activity, self-monitoring, and risk reduction.

2. All professionals working in diabetes clinic should give diabetes education and counselling during every visit on importance of self-care practices and should not rely on medical intervention only.

3. Arba Minch Hospital Administers and Arba Minch Hospital Diabetic Association Coordinators should design strategies to avail facilities to monitor $\mathrm{HbAlc}$ level of patients; hence it is more reliable method of determination of glycaemic level.

4. To researchers who are interested in the area it is important to conduct, further follow-up study to look into the sustainability of the self-care behaviour and its effect on diabetic related morbidity since observing behaviour is better than studying it as reported.

\section{Acknowledgments}

Above all our special thanks go to God Almighty for giving us health, and courage to conduct this research. We are indebted to Arbaminch College of health sciences, Jimma University, all participants, staff nurses in the diabetic clinic, and health personnel at Arba Minch General Hospital, friends, and colleagues who encouraged and supported along this journey.

\section{Competing Interests}

There is no financial or personal relationship(s) which may have inappropriately influenced us in writing this article.

\section{Authors' Contributions}

Mende Mensa conceived the study and Tesfahun Chanie was first consultan during writing this paper. Lamessa Dube worked on the statistical analysis and polished the language. All of us participated in drafting the article, final reviews and approved the final manuscript.

\section{References}

1. Mersal FA (2013) Improving Self Care Practice for Adults with Type 2 Diabetes Mellitus. Innovative Journal of Medical and Health Science 22: 93-101.

2. Yavari A (2011) Effect of Exercise on Psychological Well-being in T2 diabetes Journal of stress physiology \& biochemistry 7

3. Standards of medical care in diabetes (2011) American Diabetes Association: Diabetes care 34: S11-S61.

4. Standard of medical care in diabetes (2008) American Diabetic Association. Diabetes care 31: 43-46.

5. Definition (2007) Diagnosis and Classification of Diabetes Mellitus and its complications. Report of a WHO consultation Geneva.

6. Diabetes atlas Sixth edition (2013) IDF.

7. Shaw JE, Sicree RA, Zimmet PZ (2010) Global estimates of the prevalence of diabetes for 2010 and 2030. Diabetes Res Clin Pract 87: 4-14.

8. Tadele ATB, Endalew H (2014) Self-care practice and its predictors among adults with diabetes mellitus on follow up at nekemte hospital diabetic clinic west ethiopia. World Journal of Medicine and Medical Science 2: 1-16.

9. da Rocha Fernandes J, Ogurtsova K, Linnenkamp U, Guariguata L, Seuring T, et al. (2016) IDF Diabetes Atlas estimates of 2014 global health expenditures on diabetes. Diabetes Res Clin Pract 117: 48-54.

10. Tuei VC, Maiyoh GK, Ha CE (2010) Type 2 diabetes mellitus and obesity in sub-Saharan Africa. Diabetes Metab Res Rev 26: 433-445. 
Citation: Sorato MM, Tesfahun C, Lamessa D (2016) Levels and Predictors of Adherence to Self-care Behaviour among Adult Type 2 Diabetics at Arba Minch General Hospital, Southern Ethiopia. J Diabetes Metab 7: 684. doi:10.4172/2155-6156.1000684

Page 10 of 11

11. Kolling M, Winkley K, von Deden M (2010) For someone who's rich, it's not a problem. Insights from Tanzania on diabetes health-seeking and medical pluralism among Dar es Salaam's urban poor. Global Health 6: 8

12. Mbanya JC, Motala AA, Sobngwi E, Assah FK, Enoru ST (2010) Diabetes in sub-Saharan Africa. Lancet 375: 2254-2266.

13. Feleke YEF (2007) Cost of Hospitalization of Diabetic patients admitted at Tikur Anbessa specialized Hospital, Addis Ababa, Ethiopia. Ethiop med J 450: 275282.

14. Yemane YBT (2007) Type 2 Diabetes Mellitus in Jimma Town, Southwest Ethiopia. Ethiopia JHealth science 17: 21-25.

15. Diabetes in Ethiopia (2009) Ethiopian diabetes association.

16. Gul N (2010) Knowledge, attitudes and practices of type 2 diabetic patients. J Ayub Med Coll Abbottabad 22: 128-131.

17. Standards of Medical Care in Diabetes (2014) American Diabetes Association (ADA). Diabetes Care 37.

18. Guidelines for the Practice of Diabetes Self-Management Education and Training (DSME/T) (2010) American Association of Diabetes Educators Chicago. Illinois 2: 17-29.

19. Jennings A, Powell J, Armstrong N, Sturt J, Dale J (2009) A virtual clinic for diabetes self-management: pilot study. J Med Internet Res 11: e10.

20. Funnell MBM, Childs B (2008) National standards for diabetes self-management education. Diabetes care 31.

21. Grant RW, Kirkman MS (2015) Trends in the evidence level for the American Diabetes Association's "Standards of Medical Care in Diabetes" from 2005 to 2014. Diabetes Care 38: 6-8

22. Abdo MME (2009) Effectiveness of health education program for type 2 diabetes mellitus patients attending Zagazig university diabetes clinic Egypt. Public health journal of Egypt 85: 3-18.

23. Armstrong N (2015) Standards of Medical Care in Diabetes. Diabetes Care 38

24. Addisu YEA, Hailu E (2014) Assessment of Diabetic Patient Perception on Diabetic Disease and Self-Care Practice in Dilla University Referral Hospital South Ethiopia. J Metabolic Synd 3: 166.

25. Mohebi S, Azadbakht L, Feizi A, Sharifirad G, Kargar M (2013) Structural role of perceived benefits and barriers to self-care in patients with diabetes. $J$ Educ Health Promot 2: 37

26. Narayan KMV, Kanaya AM (2006) Diabetes: Disease Control Priorities in Developing Countries. 2nd ednWashington (DC): World Bank Chapter 30: 591 603

27. Alberti KG, Zimmet P, Shaw J (2007) International Diabetes Federation: a consensus on Type 2 diabetes prevention. Diabet Med 24: 451-463.

28. Mensing CBJ, Cypress M, Weinger K, Mulcahy K (2005) National standards for diabetes self-management education. Diabetes Care 28: S72-S79.

29. Diabetes education training manual for sub-Saharan Africa (2005) International Diabetes Federation Africa Region 23: 15-19.

30. Tan MY, Magarey J (2008) Self-care practices of Malaysian adults with diabetes and sub-optimal glycaemic control. Patient Educ Couns 72: 252-267.

31. Zhou Y, Liao L, Sun M, He G (2013) Self-care practices of Chinese individuals with diabetes. Exp Ther Med 5: 1137-1142.

32. Shrivastava SR, Shrivastava PS, Ramasamy J (2013) Role of self-care in management of diabetes mellitus. J Diabetes Metab Disord 12: 14.

33. Aanand V (2009) Implementation plans and self-monitoring of blood glucose in diabetics. [Dissertation], Michigan University 2: 60

34. Okolie VEI, Ihanacho O (2009) Knoweledge of diabetes management and control by diabetic's patients at Federal Medical Center UmuahiaAbia State Nigeria. International Journal of medicine and Medical sciences 1.

35. Maizlish NA, Shaw B, Hendry K (2004) Glycemic control in diabetic patients served by community health centers. Am J Med Qual 19: 172-179.

36. Hertz RP, Unger AN, Lustik MB (2005) Adherence with pharmacotherapy for type 2 diabetes: a retrospective cohort study of adults with employer-sponsored health insurance. Clin Ther 27: 1064-1073.

37. Brown SA, Blozis SA, Kouzekanani K, Garcia AA, Winchell M, et al. (2005)
Dosage effects of diabetes self-management education for Mexican Americans: the Starr County Border Health Initiative. Diabetes Care 28: 527-532.

38. Padma KBS, Bodhare T (2012) Evaluation of Knowledge And Self Care Practices And Their Role in Disease Management. National Journal of Community Medicine 3: 3-6.

39. Endalew H, Tefera B (2012) Self-care practice and glycaemic control amongst adults with diabetes at the Jimma University Specialized Hospital in south-west Ethiopia: A cross-sectional study. Afr JPrm Health Care Fam Med 4: 12-20.

40. Kalayou B, Haftu G (2013) Adherence to Diabetes Self-Management Practices among Type li Diabetic Patients in Ethiopia; A Cross Sectional Study. Greener Journal of Medical Sciences 3: 211-221.

41. Barnett A, Strojek K (2008) The efficacy of self-monitoring of blood glucose in the management of patients with type 2 diabetes treated with a gliclazide modified release-based regimen. A multicentre, randomized, parallel-group, 6-month evaluation (DINAMIC 1 study). Diabetes Obes Metab 10: 1239-1247.

42. Rodbard H, Braithwaite S (2007) American Association of Clinica Endocrinologists medical guidelines for clinical practice for the management of diabetes mellitus. Endocr Pract 13: 3-68.

43. Laura MC, Giel N (2005) Self-Monitoring of Blood Glucose in Patients With Type 2 Diabetes Who Are Not Using Insulin. Diabetes care 28: 6

44. Boulé NG, Kenny GP, Haddad E, Wells GA, Sigal RJ (2003) Meta-analysis of the effect of structured exercise training on cardiorespiratory fitness in Type 2 diabetes mellitus. Diabetologia 46: 1071-1081

45. Abubakari AR, Lauder W, Jones MC, Kirk A, Agyemang C, et al. (2009) Prevalence and time trends in diabetes and physical inactivity among adult West African populations: the epidemic has arrived. Public Health 123: 602 614

46. Geneva (2010) Global status report on noncommunicable diseases Switzerland: World Health Organization 12: 15-33.

47. Ayele K, Tesfa B, Abebe L, Tilahun T, Girma E (2012) Self care behavio among patients with diabetes in Harari, Eastern Ethiopia: the health belief model perspective. PLoS One 7: e35515.

48. Abebe SM, Berhane Y, Worku A (2014) Barriers to diabetes medication adherence in North West Ethiopia. Springerplus 3: 195.

49. Brown MT, Bussell JK (2011) Medication adherence: WHO cares? Mayo Clin Proc 86: 304-314.

50. Wabe NT, Angamo MT, Hussein S (2011) Medication adherence in diabetes mellitus and self management practices among type-2 diabetics in Ethiopia. $\mathrm{N}$ Am J Med Sci 3: 418-423.

51. Adisa R, Fakeye TO (2013) Effect of number and type of antidiabetes medications on adherence and glycemia of ambulatory type 2 diabetes patients in southwestern Nigeria. Pharm Pract (Granada) 11: 156-165.

52. Gesare OB (2013) Assessement of the level of knowledge,self-care practice and glycemic control among patients with type 2 diabetes attending the diabetes clinic at kenyatta national hospital. Diabetes Research and Clinical Practice 84: 303-310.

53. William K, Eva W (2010) Knowledge, attitude and practices related to diabetes among community members in four provinces in Kenya: a cross-sectional study. AfrJ Prm Health Care Fam Med 4: 1.

54. Fisher E, Devellis B (2007) Healthy coping, negative emotions, and diabetes management: a systematic review and appraisal. Diabetes Educ 33: 10801103.

55. Berg CA, King PS, Butler JM (2011) Parental involvement and adolescents' diabetes man-agement: The mediating role of self-efficacy and externalizing and internalizing behaviors. Journal of Pediatric Psychology 36: 329- 339.

56. Modi AC, Pai AL, Hommel KA, Hood KK, Cortina S, et al. (2012) Pediatric self-management: a framework for research, practice, and policy. Pediatrics 129: e473-485.

57. Brody GH, Kogan SM, Murry VM (2008) Psychological functioning, support for self-management, and glycemic control among rural African American adults with diabetes mellitus type 2. Health Psychology 27: S83-S90.

58. Tang TS, Brown MB, Funnell MM, Anderson RM (2008) Social support, quality of life, and self-care behaviors amongAfrican Americans with type 2 diabetes. Diabetes Educ 34: 266-276. 
Citation: Sorato MM, Tesfahun C, Lamessa D (2016) Levels and Predictors of Adherence to Self-care Behaviour among Adult Type 2 Diabetics at Arba Minch General Hospital, Southern Ethiopia. J Diabetes Metab 7: 684. doi:10.4172/2155-6156.1000684

Page 11 of 11

59. Kessain S (2009) Factors Influencing Self-Care Behaviors of Diabetic Patients In Diabetes Mellitus. Changhan Hospital, Roi Et Province, Thailand 23: 12

60. Al-Maskari F, Al-Kaabi JM (2013) Knowledge, Attitude and Practices of Diabetic Patients in the United Arab Emirates. PLoS one 8: 1.

61. Odili V (2011) Knowledge of Diabetes Mellitus in a Nigerian City. Journal of Pharmaceutical Research 10: 637-642.

62. Baumann LC, Opio CK, Otim M, Olson L, Ellison S (2010) Self-care beliefs and behaviors in Ugandan adults with type 2 diabetes. Diabetes Educ 36: 293-300.

63. Guainine LM (2007) An assessment of the level of knowledge about diabetes mellitus among diabetic patients in a primary healthcare setting. SA Fam Pract 49: 16.

64. Berhe K, Kahsay H (2014) Assessment of Diabetes Knowledge and its Associated Factors among Type 2 Diabetic Patients in Mekelle and Ayde Referral Hospitals, Ethiopia. J Diabetes Metab 5: 378.

65. Asnakew FS, Taye AH (2013) Assessment of the Level and Associated Factors with Knowledge and Practice of Diabetes Mellitus among Diabetic Patients Attending at FelegeHiwot Hospital, Northwest Ethiopia. Clinical Medicine Research 2: 110-120.

66. Heinrich E, de Vries N (2010) Self-management interventions for type2 diabetes: a systematic review. EDN autumn 7: 2

67. Rannj JC (2002) Evaluation of a comprehensive diabetes disease management program: Progress in the struggle for sustained behavior change. Dis Manag 5: $77-86$

68. Norris SL, Lau J, Smith SJ, Schmid CH, Engelgau MM (2002) Self-management education for adults with type 2 diabetes: a meta-analysis of the effect on glycemic control. Diabetes Care 25: 1159-1171.

69. Zenger M, van der Feltz-Cornelis C (2014) Validation of the Patient-DoctorRelationship Questionnaire (PDRQ-9) in a Representative Cross-Sectional German Population Survey. PLoS ONE 9: 3

70. Al-Qazaz HKh, Hassali MA, Shafie AA, Sulaiman SA, Sundram S, et al. (2010) The eight-item Morisky Medication Adherence Scale MMAS: translation and validation of the Malaysian version. Diabetes Res Clin Pract 90: 216-221.

71. Garcia AA, Villagomez ET, Brown SA, Kouzekanani K, Hanis CL (2001) The Starr County Diabetes Education Study: development of the Spanish-language diabetes knowledge questionnaire. Diabetes Care 24: 16-21.

72. Toobert DJ, Hampson SE, Glasgow RE (2000) The summary of diabetes selfcare activities measure: results from 7 studies and a revised scale. Diabetes Care 23: 943-950.

73. Krousel-Wood M, Islam T, Webber LS, Re RN, Morisky DE, et al. (2009) New medication adherence scale versus pharmacy fill rates in seniors with hypertension. Am J Manag Care 15: 59-66.

74. Binh TQ, Phuong PT, Nhung BT, Thoang DD, Van Thang P, et al. (2012) Prevalence and correlates of hyperglycemia in a rural population, Vietnam: implications from a cross-sectional study. BMC Public Health 12: 939.
75. Kaur SSJ, Kawaljit K (2014) Determinants of the glycemic status and its relationship with cardiovascular risk factors. Journal of Biochemical and Pharmacological Researc 2: 159-166.

76. Dudekula A (2012) Correlation b/n blood sugars and body mass index with blood pressures among type 2 diabetic adults. Asian J exp biol Sci 3: 2 .

77. Mahfouz EM, Awadalla HI (2011) Compliance to diabetes self-management in rural El-Mina, Egypt. Cent Eur J Public Health 19: 35-41.

78. Naglaa MA (2010) Effectiveness Of Health Education Program for Type 2 Diabetes Mellitus Patients Attending Zigzag University Diabetes Clinic, Egypt. Egypt Public Health Assoc 85: 4.

79. Nouwen A, Balan AT (2011) Longitudinal motivational predictors of dietary self-care and diabetes control in adults with newly diagnosed type 2 diabetes mellitus. Health Psychology 30: 771e9.

80. Kamuhabwa AR, Charles E (2014) Predictors of poor glycemic control in type 2 diabetic patients attending public hospitals in Dar es Salaam. Drug Healthc Patient Saf 6: 155-165.

81. Najla S, Zahra A (2013) Factors Influencing Dietary Practice among Type 2 Diabetics. Bahrain Medical Bulletin 35.

82. Bray GA (2008) Lifestyle and pharmacological approaches to weight loss: efficacy and safety. J Clin Endocrinol Metab 93: S81-88.

83. Adisa R, Fasanmade A (2011) Medication adherence among ambulatory patients with type 2 diabetes in a tertiary healthcare setting in southwestern Nigeria. Pharmacy Practice (Internet) 9: 72-81.

84. Cramer JA (2004) A systematic review of adherence with medications for diabetes. Diabetes Care 27: 1218-1224

85. Willett LR (2012) ACP Journal Club. Meta-analysis: self-monitoring in noninsulin-treated type 2 diabetes improved $\mathrm{HbA} 1 \mathrm{c}$ by $0.25 \%$. Ann Intern Med 156 : JC6-12.

86. Al-Akour NA, Alaoui AM (2011) Glycemic Control and Its Determinants among Patients with type 2 Diabetes Mellitus Attending a Teaching Hospital. J Diabetes Metab 22: 129.

87. Bains SS Associations between health literacy, diabetes knowledge, selfcare behaviors, and glycemic control in a low income population with type 2 diabetes. Diabetes Technol Ther 13: 335-341.

88. Abrahim M (2011) A Systematic Literature Review on Factors Contributing to Self-Care among Type 2 Diabetes Mellitus Patients.

89. Bai YL, Chiou CP, Chang YY (2009) Self-care behaviour and related factors in older people with Type 2 diabetes. J Clin Nurs 18: 3308-3315.

90. Olshansky E, Sacco D, Fitzgerald K, Zickmund S, Hess R, et al. (2008) Living with diabetes: normalizing the process of managing diabetes. Diabetes Educ 34: 1004-1012.

91. Russell LB, Suh DC, Safford MA (2005) Time requirements for diabetes selfmanagement: too much for many? J Fam Pract 54: 52-56. 